\title{
Construction of an $n$-Body Potential for Revealing the Atomic Mechanism for Direct Alloying of Immiscible Tungsten and Copper
}

\author{
Tao Zeng, Fei Li and Yuan Huang *(D)
}

check for updates

Citation: Zeng, T.; Li, F.; Huang, Y. Construction of an $n$-Body Potential for Revealing the Atomic Mechanism for Direct Alloying of Immiscible Tungsten and Copper. Materials 2021, 14, 5988. https://doi.org/ $10.3390 /$ ma14205988

Academic Editor: Christian Motz

Received: 4 September 2021

Accepted: 8 October 2021

Published: 12 October 2021

Publisher's Note: MDPI stays neutral with regard to jurisdictional claims in published maps and institutional affiliations.

Copyright: (c) 2021 by the authors. Licensee MDPI, Basel, Switzerland. This article is an open access article distributed under the terms and conditions of the Creative Commons Attribution (CC BY) license (https:/ / creativecommons.org/licenses/by/ $4.0 /)$.
Institute of Advanced Metallic Materials, School of Materials Science and Engineering, Tianjin University, Tianjin 300350, China; taozeng@tju.edu.cn (T.Z.); lifei14010@163.com (F.L.)

* Correspondence: yi_huangyuan@tju.edu.cn

\begin{abstract}
W-Cu laminated composites are critical materials used to construct nuclear fusion reactors, and it is very important to obtain direct alloying between $\mathrm{W}$ and $\mathrm{Cu}$ at the $\mathrm{W} / \mathrm{Cu}$ interfaces of the composites. Our previous experimental studies showed that it is possible to overcome the immiscibility between $\mathrm{W}$ and $\mathrm{Cu}$ and obtain direct alloying when the alloying temperature is close to the melting point of $\mathrm{Cu}$. Because the $\mathrm{W}-\mathrm{Cu}$ interatomic potentials published thus far cannot accurately reproduce the alloying behaviors of immiscible $\mathrm{W}$ and $\mathrm{Cu}$, an interatomic potential suitable for the $\mathrm{W}$ $\mathrm{Cu}$ system has been constructed in the present study. Based on this potential, direct alloying between $\mathrm{W}$ and $\mathrm{Cu}$ at high temperature has been verified, and the corresponding diffusion mechanism has been studied, through molecular dynamics (MD) simulations. The results indicate that the formation of an amorphous $\mathrm{Cu}$ layer at the $\mathrm{W} / \mathrm{Cu}$ interface plays a critical role in alloying because it allows $\mathrm{Cu}$ atoms to diffuse into $\mathrm{W}$. The simulation results for direct alloying between $\mathrm{W}$ and $\mathrm{Cu}$ can be verified by experimental results and transmission electron microscopy observations. This indicates that the constructed $\mathrm{W}-\mathrm{Cu}$ potential can correctly model the high-temperature performance of the $\mathrm{W}-\mathrm{Cu}$ system and the diffusion mechanism of direct alloying between $\mathrm{W}$ and $\mathrm{Cu}$.
\end{abstract}

Keywords: W-Cu immiscible system; direct alloying; $n$-body potential; molecular dynamics simulations

\section{Introduction}

Tungsten-copper ( $\mathrm{W}-\mathrm{Cu})$ laminated composites, due to the high melting point, high sputtering resistance and low tritium retention property of $\mathrm{W}$ and the good thermal conductivity of $\mathrm{Cu}$, have been widely used in many fields, such as plasma facing materials (PFMs), high temperature resistant materials, microelectronic materials and packaging materials [1-3]. However, as a typical immiscible binary metal system, the heat of formation for the $\mathrm{W}-\mathrm{Cu}$ system $\left(\Delta \mathrm{Hf}=+33 \mathrm{kJmol}^{-1}\right)[4]$ is positive, which means that direct alloying between $\mathrm{W}$ and $\mathrm{Cu}$ is very difficult. Therefore, it is also difficult to prepare $\mathrm{W}$-Cu laminated composites by traditional methods [5]. At present, direct alloying between $\mathrm{W}$ and $\mathrm{Cu}$ can be realized through some nonequilibrium processing techniques [6-9] that form $\mathrm{W}-\mathrm{Cu}$ solid solutions. For example, some metastable $\mathrm{W}-\mathrm{Cu}$ phases have been fabricated through mechanical alloying [10], ion beam mixing [11] and direct diffusion methods [12]. A typical example is the metastable hcp phase synthesized by Zhang et al. in properly designed $\mathrm{W}-\mathrm{Cu}$ multilayered films through the ion beam mixing method [11]. In addition, our previous experimental studies demonstrated that it is feasible to realize direct alloying between $\mathrm{W}$ and $\mathrm{Cu}$ through high-temperature structure induced alloying (HTSIA) methods at temperatures close to the melting point of $\mathrm{Cu}\left(\mathrm{T}_{\mathrm{mCu}}\right)[12,13]$, i.e., in the range from $0.81 \mathrm{~T}_{\mathrm{mCu}}$ to $0.97 \mathrm{~T}_{\mathrm{mCu}}$. The thermodynamic driving force for direct alloying is the surface energy and storage energy produced during the processing of raw materials [14]. This method is especially suitable for the preparation of $\mathrm{W}-\mathrm{Cu}$ laminated composites. 
To understand the atomic-scale structural characteristics and underlying mechanism of nonequilibrium W-Cu alloys synthesized through direct alloying, ab initio calculations and molecular dynamics (MD) simulations have been performed in recent decades [15-18]. To carry out MD simulations, some interatomic potentials $[19,20]$ have been developed for W-Cu systems. For example, Gong et al. [19] constructed an interatomic potential and used it to carry out MD simulations to study the amorphization transition and determine the glass-forming range of the $\mathrm{W}-\mathrm{Cu}$ system. Their simulation results show that $\mathrm{W}-\mathrm{Cu}$ bonding occurs at low temperatures (300 K). In a study proposed by Kong et al. [20], an embedded atom method (EAM) potential was used to carry out MD simulations that showed the difficulty for $\mathrm{Cu}$ and $\mathrm{W}$ atoms to interdiffuse in the temperature range of 300-900 K. Obviously, these published W-Cu potentials are not accurate enough to explain the experimental observations of direct alloying between $\mathrm{W}$ and $\mathrm{Cu}$ by diffusion in the temperature range from $0.81 \mathrm{~T}_{\mathrm{mCu}}$ to $0.97 \mathrm{~T}_{\mathrm{mCu}}$. Therefore, it is necessary to construct an $n$-body potential that can be used to analyze the diffusion mechanism of direct alloying between $\mathrm{W}$ and $\mathrm{Cu}$.

In this paper, a new n-body potential for the $\mathrm{W}-\mathrm{Cu}$ system is constructed. The construction process roughly comprises the following steps: (a) appropriate expressions for the $\mathrm{W}-\mathrm{Cu}$ potential are determined; (b) the parameters for the $\mathrm{W}-\mathrm{W}$ and $\mathrm{Cu}-\mathrm{Cu}$ components of the $\mathrm{W}-\mathrm{Cu}$ potential are determined by solving a set of linear equations and fitting experimental values; (c) the physical properties, such as lattice constants and cohesive energies, of some fictitious solid solutions are determined by ab initio calculations and used to construct the $\mathrm{W}-\mathrm{Cu}$ component of the $\mathrm{W}-\mathrm{Cu}$ potential; and (d) the validity of the new $\mathrm{W}-\mathrm{Cu}$ potential is verified by comparing the results of an MD simulation using the $\mathrm{W}-\mathrm{Cu}$ potential with experimental results. The abovementioned MD simulation mainly applies the new $n$-body potential to simulate the physical and thermal properties of pure $\mathrm{W}$ and $\mathrm{Cu}$ and diffusion behavior during the direct alloying of $\mathrm{W}$ and $\mathrm{Cu}$. The main experiment was to use atomic-scale resolution high-angle annular dark-field scanning transmission electron microscopy to characterize the $\mathrm{W} / \mathrm{Cu}$ interface constructed through direct alloying of $\mathrm{W}$ and $\mathrm{Cu}$. The simulation results agree well with interfacial observations and previous experimental results for alloying $\mathrm{W}$ and $\mathrm{Cu}$, indicating that the new $\mathrm{W}-\mathrm{Cu}$ potential can model W-Cu alloying and reveal the corresponding diffusion mechanism.

\section{Methods}

\subsection{Construction of the W-Cu Interatomic Potentials}

The W-Cu potentials published thus far, which are all $n$-body potentials, can be divided into two major categories: the embedded atom method (EAM) and the Finnis-Sinclair (FS) potentials [16,17]. All of them consist of three components: the $\mathrm{W}-\mathrm{W}$ potential, $\mathrm{Cu}-\mathrm{Cu}$ potential and $\mathrm{W}-\mathrm{Cu}$ cross potential. The published $\mathrm{W}-\mathrm{Cu}$ potentials are not sufficiently accurate to simulate the experimental phenomenon that is the focus of this study. We believe that the main reason for this limitation is that the mutual attraction between $W$ atoms originating from the $\mathrm{W}-\mathrm{W}$ potential part of the $\mathrm{W}-\mathrm{Cu}$ potential is very strong, which eventually leads to deviations in the interaction between $\mathrm{W}$ and $\mathrm{Cu}$ in the $\mathrm{W}-\mathrm{Cu}$ cross potential. One of the pieces of evidence for the strong mutual attraction between $\mathrm{W}$ atoms is the MD simulation of the melting point of $\mathrm{W}$ using these $\mathrm{W}-\mathrm{Cu}$ potentials. For example, the W/Cu EAM potential presented by Gong et al. [19] was developed by modifying the $n$-body $\mathrm{W}-\mathrm{Cu}$ potential constructed by Johnson et al. When this potential was used to carry out MD simulations of the melting behavior of $W$ metal, it resulted in a very high melting point for $\mathrm{W}(4625 \mathrm{~K})$ [19], while the true melting point of $\mathrm{W}$ is $3695 \mathrm{~K}$ [21]. This indicates that concerns about the melting point of $\mathrm{W}$ should be maintained throughout the whole construction process of the $\mathrm{W}-\mathrm{Cu}$ potential. Another reason why some $\mathrm{W}-\mathrm{Cu}$ potentials are not suitable to simulate the HTSIA experimental phenomenon is that the physical properties of the nonequilibrium alloy structures of the system were not fully considered during the construction process. For example, the potentials constructed by Kong et al. [20] only employed a transferable formula proposed by Johnson [21] without 
fitting the cohesive energies and lattice constants of the nonequilibrium alloy structures. When this $\mathrm{W}-\mathrm{Cu}$ potential is used to carry out MD simulations of direct alloying between $\mathrm{W}$ and $\mathrm{Cu}$, the simulation results predict that interdiffusion cannot occur.

To solve the above problems and construct a more accurate $\mathrm{W}-\mathrm{Cu}$ potential, some methods have been adopted in this paper. The whole construction process is as follows. First, the original Finnis-Sinclair (FS) potential is adopted [22] to construct the $n$-body potential for the immiscible W-Cu system. This is mainly because the FS potential is capable of reproducing the physical properties of transition metals with bcc structures [23] based on the second-moment approximation. According to the formalisms of the original FS potential, the formula for the total $E_{\text {tot }}$ be expressed as follows [22]:

$$
E_{\text {tot }}=\frac{1}{2} \sum_{i j} V_{i j}\left(r_{i j}\right)+\sum_{i} F_{i}\left(\rho_{i}\right)
$$

where $E_{\text {tot }}$ is the total energy of the system, $V_{i j}\left(r_{i j}\right)$ and $r_{i j}$ are the conventional central pair potential and the distance between the two corresponding atoms, respectively. $F_{i}\left(\rho_{i}\right)$ is the embedded energy, and $\rho_{i}$ is the electronic density at atom $i$ due to all its neighbors.

According to Ackland et al. [24], because of the electronic structure difference, the original FS formalism is not very effective for face-centered cubic (fcc) metals, and calculations that use the FS potential to determine thermal expansion coefficients of crystals produce values that deviate from experimental values. Furthermore, extending the FS formalism from pure metals to alloys is relatively inconvenient. Accordingly, K. P. Tai [25] proposed the extended-FS potential, which provides an extension to the original FS formalism and has a simple analytic form. The extended-FS potential can correctly describe the physical properties of some noble metal systems with an fcc structure. Therefore, at the present time, the specific expressions for the central pair potentials $V_{W}(r)$ and $V_{\mathrm{Cu}}(r)$ in Equation (1) are given by the following formulas, where Equation (2) [22] is the original pair potential for $\mathrm{W}$ with a bcc structure and Equation (3) [26] is the extended pair potential for Cu with an fcc structure,

$$
\begin{gathered}
V_{W}(r)= \begin{cases}(r-c)^{2}\left(c_{0}+c_{1} r+c_{2} r^{2}\right), & r \leq c \\
0, & r>c\end{cases} \\
V_{\mathrm{Cu}}(r)= \begin{cases}(r-c)^{2}\left(c_{0}+c_{1} r+c_{2} r^{2}+c_{3} r^{3}+c_{4} r^{4}\right), & r \leq c \\
0, & r>c\end{cases}
\end{gathered}
$$

where $r$ is the interatomic distance, $c$ is the cutoff distance of the pair potential, and $c_{0}, c_{1}$, $c_{2}, c_{3}$ and $c_{4}$ are the potential parameters to be fitted.

The specific expressions of the embedded energy $\left(F_{i}\left(\rho_{i}\right)\right)$ and electronic density $\left(\rho_{i}\right)$ in Equation (1) are as follows [22,26]:

$$
\begin{gathered}
F\left(\rho_{i}\right)=-\sqrt{\rho_{i}} \\
\rho_{i}=\sum_{i \neq j} A^{2} \phi_{i j}\left(r_{i j}\right) \\
\phi_{W}(r)= \begin{cases}(r-d)^{2}, & r \leq d \\
0, & r>d\end{cases} \\
\phi_{\mathrm{Cu}}(r)= \begin{cases}(r-d)^{2}+b^{2}(r-d)^{4}, & r \leq d \\
0, & r>d\end{cases}
\end{gathered}
$$

where $r$ is the distance between the atoms, $d$ is the electronic density function, and $b$ is the potential parameter.

The formalism of the extended-FS potential is used to construct the $\mathrm{W}-\mathrm{Cu}$ component of the $\mathrm{W}-\mathrm{Cu}$ potential. Correspondingly, the extended pair-potential $\left(V^{\mathrm{W}-\mathrm{Cu}}\left(r^{\mathrm{W}-\mathrm{Cu}}\right)\right)$, the embedded energy $\left(F^{\mathrm{W}-\mathrm{Cu}}\left(\rho_{i}^{\mathrm{W}-\mathrm{Cu}}\right)\right)$ and the electronic density $\left(\rho_{i}^{\mathrm{W}-\mathrm{Cu}}\right)$ can be expressed as follows. 


$$
\begin{aligned}
& V^{\mathrm{W}-\mathrm{Cu}}\left(r^{\mathrm{W}-\mathrm{Cu}}\right)=\left\{\begin{array}{l}
\left(r^{\mathrm{W}-\mathrm{Cu}}-c\right)^{2}\left(c_{0}+c_{1} r^{\mathrm{W}-\mathrm{Cu}}+c_{2}\left(r^{\mathrm{W}-\mathrm{Cu}}\right)^{2}+c_{3}\left(r^{\mathrm{W}-\mathrm{Cu}}\right)^{3}+c_{4}\left(r^{\mathrm{W}-\mathrm{Cu}}\right)^{4}\right), r^{\mathrm{W}-\mathrm{Cu}} \leq c \\
0, r^{\mathrm{W}-\mathrm{Cu}}>c
\end{array}\right. \\
& F^{\mathrm{W}-\mathrm{Cu}}\left(\rho_{i}^{\mathrm{W}-\mathrm{Cu}}\right)=-\sqrt{\rho_{i}^{\mathrm{W}-\mathrm{Cu}}} \\
& \rho_{i}^{\mathrm{W}-\mathrm{Cu}}=\sum_{j \neq i} A^{2} \phi^{\mathrm{W}-\mathrm{Cu}}\left(r^{\mathrm{W}-\mathrm{Cu}}\right) \\
& \phi^{\mathrm{W}-\mathrm{Cu}}\left(r^{\mathrm{W}-\mathrm{Cu}}\right)=\left\{\begin{array}{l}
\left(r^{\mathrm{W}-\mathrm{Cu}}-d\right)^{2}+b^{2}\left(r^{\mathrm{W}-\mathrm{Cu}}-d\right)^{4}, r^{\mathrm{W}-\mathrm{Cu}} \leq d \\
0, r^{\mathrm{W}-\mathrm{Cu}}>d
\end{array}\right.
\end{aligned}
$$

where $r \mathrm{~W}-\mathrm{Cu}$ is the distance between the $\mathrm{W}$ and $\mathrm{Cu}$ atoms, $c$ and $d$ are the cutoff distances of the extended pair potential and electronic density, respectively, and $c_{0}, c_{1}, c_{2}, c_{3}, c_{4}$ and $b$ are the potential parameters to be fitted.

According to the results of tight-binding theory [22], the $n$-body term-namely, the embedded energy $F_{i}\left(\rho_{i}\right)$ in Equation (4), is proportional to the square root of the total electron density function $\rho_{i}$ at atom $i$. The $\rho_{i}$ at atom $i$ can be approximated by the linear superposition of the electron density $\phi\left(r_{i j}\right)$ contributed by the neighboring atoms, which is a reasonable simplification according to the second-moment approximation [19]. The cutoff parameters $c$ and $d$ are assumed to lie between the second nearest-neighbor and third nearest-neighbor atoms of each atom in the corresponding structure. For the bcc structure, the cutoff parameters are between $a$ and sqrt $(2)^{*} a$, and for the fcc structure, they are between a and sqrt (6) $/ 2^{*} a$, where $a$ is the lattice constant of the corresponding structure. When the parameters $c_{3}$ and $c_{4}$ in Equation (3) and the parameter $b$ in Equation (7) are set to zero, the extended-FS potential is reduced to the original form.

Thus, in the present study, nine parameters $\left(A, d, c, c_{0}, c_{1}, c_{2}, c_{3}, c_{4}, b\right)$ were fitted for the $\mathrm{Cu}-\mathrm{Cu}$ potential part of the $\mathrm{W}-\mathrm{Cu}$ potential, and another six parameters $(A, d, c$, $c_{0}, c_{1}, c_{2}$ ) were fitted for the $\mathrm{W}-\mathrm{W}$ potential part of the $\mathrm{W}-\mathrm{Cu}$ potential. In addition, some experimental physical property data, such as the cohesive energy $\left(E_{c}\right)$, lattice constant $(a)$, vacancy formation energies $\left(E_{v}\right)$, bulk modules $(B)$, elastic constants $\left(C_{11}, C_{12}\right.$, and $\left.C_{44}\right)$, and pressure $(P)$, are applied to determine the $\mathrm{Cu}-\mathrm{Cu}$ and $\mathrm{W}-\mathrm{W}$ potential parts of the $\mathrm{W}-\mathrm{Cu}$ potential. The relationships between these physical properties and the corresponding potentials are described in Section A of the Supporting Information for this paper. The process for determining the parameters for the $\mathrm{W}-\mathrm{W}$ potential part of $\mathrm{W}$-Cu potential is to solve a set of linear equations by an iteration on the parameter $d$ with the experimental values of the cohesive energy, lattice constant, bulk modulus and Cauchy pressure in this paper, which is a reasonable approximation of the method proposed by Finnis and Sinclair [22]. For the $\mathrm{Cu}-\mathrm{Cu}$ potential part of the $\mathrm{W}-\mathrm{Cu}$ potential, the corresponding potential parameters are obtained through a least squares method that has been applied to minimize the fitting error of Formula (12).

$$
E R=\left(E_{C}-E_{C}^{e}\right)^{2}+P^{2}+\left(E_{v}-E_{v}^{e}\right)^{2}+\left(C_{11}-C_{11}^{e}\right)^{2}+\left(C_{12}-C_{12}^{e}\right)^{2}+\left(C_{44}-C_{44}^{e}\right)^{2}
$$

where $E_{c}^{e}, E_{v}^{e}, C_{11}^{e}, C_{12}^{e}$ and $C_{44}^{e}$ represent the experimental values of the cohesive energy $\left(E_{c}\right)$, vacancy formation energies $\left(E_{v}\right)$ and elastic constants $\left(C_{11}, C_{12}\right.$, and $\left.C_{44}\right)$, respectively. The ER term in Equation (8) represents the fitting error. A simple computer program is adopted to solve the problem of fitting optimization.

The $\mathrm{W}-\mathrm{Cu}$ cross-potential part of the $\mathrm{W}-\mathrm{Cu}$ potential has the same formalism as the $\mathrm{Cu}-\mathrm{Cu}$ potential (see Equations (8)-(11)), and the fitting process is also similar to the $\mathrm{Cu}-\mathrm{Cu}$ potential part of the $\mathrm{W}-\mathrm{Cu}$ potential. There are very few experimental data available for deriving the parameters of the $\mathrm{W}-\mathrm{Cu}$ cross potential since the $\mathrm{W}-\mathrm{Cu}$ system is essentially immiscible. To solve this problem, considering that simple structures form more easily in immiscible systems and referring to preexisting studies [18], two fictitious 
$\mathrm{W}-\mathrm{Cu}$ solid solutions with the selected structures of $\mathrm{B} 2$ and $\mathrm{L1}_{2}$ have been constructed. Then, by using the well-established Vienna ab initio simulation package (VASP) $[27,28]$, $\mathrm{ab}$ initio calculations of the lattice constants and cohesive energies were carried out for the nonequilibrium fictitious W-Cu solid solution structures. The fictitious W-Cu solid solution structures and corresponding calculation process are described in the Supporting Information for this paper. The calculation results were eventually used to fit the parameters of the W-Cu cross-potential.

\subsection{Simulation Details}

To validate the $\mathrm{W}-\mathrm{W}$ and $\mathrm{Cu}-\mathrm{Cu}$ potential parts of the $\mathrm{W}-\mathrm{Cu}$ potential, the new potential is used to calculate the physical properties of pure $\mathrm{W}$ and $\mathrm{Cu}$ metals, including the cohesive energies, lattice constants, vacancy formation energies, elastic constants and melting points of $\mathrm{W}$ and $\mathrm{Cu}$, and the results are compared with corresponding experimental values. The calculated melting point can be obtained through the two-phase simulation (TPS) method, which is more accurate than the one-phase simulation (OPS) method according to Arima et al. [29] The initial supercell with coexisting solid and liquid phases contains $20 * 20 * 20 * 2$ unit cells. During the MD simulations, the initial supercell was relaxed in the isothermal-isobaric (NPT) ensemble at desired temperatures and pressures to reach the equilibrium state. Then, the melting point was determined based on the density change [15].

To understand the atomic-scale structural characteristics and underlying mechanism of nonequilibrium W-Cu alloys, a classical molecular dynamics code (LAMMPS [30]) based on the theoretical framework of Newtonian mechanics has been applied to simulate direct alloying. Through the simulation, the atomic-scale structure evolution, diffusion mechanism and influence of temperature during direct alloying can also be revealed. In the present study, as shown in Figure 1, a W-Cu interface simulation model consisting of $211,680 \mathrm{Cu}$ atoms and 138,240 $\mathrm{W}$ atoms was constructed. The dimensions of the unit cell were $42 * 42 * 30\left(a_{\mathrm{Cu}}\right)$ and $48 * 48 * 30\left(a_{\mathrm{W}}\right)$, where $a_{\mathrm{Cu}}$ and $a_{\mathrm{W}}$ were the lattice constants of $\mathrm{Cu}$ and $W$, respectively. The reason for setting the sizes was because $48 / 42=1.143$ was very close to $a_{\mathrm{Cu}} / a_{\mathrm{W}}=1.144$. The contact surface between the upper $(\mathrm{W})$ and lower $(\mathrm{Cu})$ layers is an ideal (100) crystal plane with the [1 000$],\left[\begin{array}{lll}0 & 1 & 0\end{array}\right]$ and [ $\left[\begin{array}{lll}0 & 0 & 1\end{array}\right]$ directions parallel to the $x, y$, and $z$ axes, respectively. To avoid strong interactions when $\mathrm{W}$ and $\mathrm{Cu}$ atoms were extremely close, a $3 \AA$ initial gap was added between the $W$ and $C u$ layers at the initial interface [31]. In the $x$ - and $y$-axes of the model, periodic boundary conditions were applied. Translational motions in the $z$-axis direction of the five atomic layers in the lower surface of $\mathrm{Cu}$ and the upper surface of $\mathrm{W}$ were fixed during the simulation.

During the simulations, the whole system was first relaxed in the NPT ensemble with zero external pressure at $300 \mathrm{~K}$ for $100 \mathrm{ps}$. After this initial equilibration run, the system was rapidly heated to the selected simulation temperature. Considering the necessary temperatures for atoms at the interface to diffuse into the opposite side are commonly between 0.6-0.8 $T_{\mathrm{m}}$ [32] and the melting points of $\mathrm{Cu}$ and $\mathrm{W}$ are $1358 \mathrm{~K}$ and $3695 \mathrm{~K}$, respectively, the simulation temperatures were chosen as $900 \mathrm{~K}, 1000 \mathrm{~K}, 1100 \mathrm{~K}, 1200 \mathrm{~K}$ and $1300 \mathrm{~K}$. Subsequently, the simulation of the interface model runs at the specified temperatures in the same NPT ensemble to achieve a satisfactorily stable state in which the thermodynamic data of the system do not change significantly. The temperature of interdiffusion of $\mathrm{W}$ and $\mathrm{Cu}$ was determined by looking for the temperature at which diffusion can obviously occur according to the simulation results.

The diffusion mechanism of direct alloying between $\mathrm{Cu}$ and $\mathrm{W}$ can be discussed by analyzing the atomic coordinates, concentration distribution curves, pair correlation functions $(g(r))$ and fine-scale density profiles $\left(\rho_{\alpha}(z)\right)$ obtained from the final simulation results. The concentration distribution curves were calculated to define the distribution of each component along the $\mathrm{z}$ axis, from which the diffusion distance during alloying between $\mathrm{W}$ and $\mathrm{Cu}$ can be determined. The analyses of the pair correlation functions 
$(g(r))$ and the fine-scale density profiles $\left(\rho_{\alpha}(z)\right)$ are described in Sections C and D of the Supporting Information for this paper, respectively.

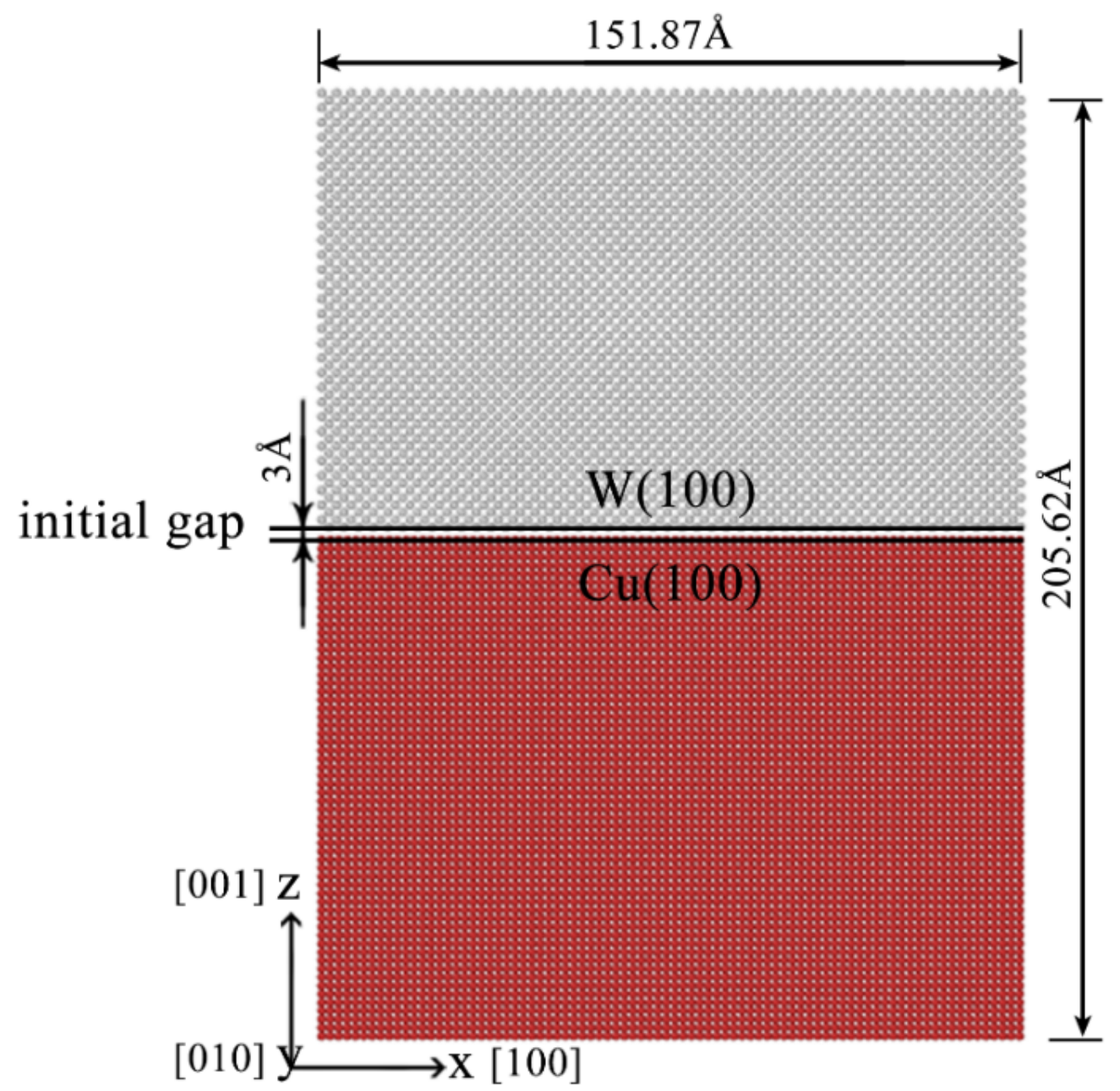

Figure 1. Initial interface model used for molecular dynamic simulations of direct alloying between $\mathrm{Cu}$ and $\mathrm{W}$, where the upper layer is the $\mathrm{W}$ layer, and the lower layer is the $\mathrm{Cu}$ layer.

\section{Results and Discussion}

3.1. Validation of the New W-Cu Potential through the Simulation of Physical Properties

The obtained parameters of the $\mathrm{Cu}-\mathrm{Cu}, \mathrm{W}-\mathrm{W}$ and $\mathrm{W}-\mathrm{Cu}$ components of the $\mathrm{W}-\mathrm{Cu}$ potential in this paper are listed in Table 1.

Table 1. Obtained parameters for the $\mathrm{Cu}-\mathrm{Cu}, \mathrm{W}-\mathrm{W}$ and $\mathrm{W}-\mathrm{Cu}$ components of the $\mathrm{W}-\mathrm{Cu}$ potential.

\begin{tabular}{ccccccc}
\hline & $\mathbf{C u}-\mathbf{C u}$ & $\sigma$ & $\mathbf{W}-\mathbf{W}$ & $\sigma$ & $\mathbf{W}-\mathbf{C u}$ & $\sigma$ \\
\hline$A\left(\mathrm{eV} \cdot \AA^{-1}\right)$ & 0.732311 & 0.017181 & 1.830783 & 0.009250 & -0.851995 & 0.043304 \\
$d(\AA)$ & 3.983654 & 0.036376 & 4.414750 & 0.008165 & 4.270928 & 0.069296 \\
$c(\AA)$ & 3.777141 & 0.010236 & 3.252641 & 0.003195 & 3.761555 & 0.073371 \\
$c_{0}\left(\mathrm{eV} \cdot \AA^{-2}\right)$ & 2.126664 & 0.063405 & 55.424876 & 3.755775 & 20.500143 & 1.524143 \\
$c_{1}\left(\mathrm{eV} \cdot \AA^{-3}\right)$ & -0.980911 & 0.049285 & -40.097017 & 4.545578 & -26.984701 & 1.276844 \\
$c_{2}\left(\mathrm{eV} \cdot \AA^{-4}\right)$ & 0.002647 & 0.000674 & 7.453343 & 1.459553 & 11.890381 & 0.069772 \\
$c_{3}\left(\mathrm{eV} \cdot \AA^{-5}\right)$ & 0.012049 & 0.004721 & 0 & 0 & -1.744063 & 0.02767 \\
$c_{4}\left(\mathrm{eV} \cdot \AA^{-6}\right)$ & 0.006451 & 0.001685 & 0 & 0 & 0 & 0 \\
$b\left(\AA^{-2}\right)$ & 0.525082 & 0.029941 & 0 & 0 & 0 & 0 \\
\hline
\end{tabular}


As stated above, the physical properties of pure $\mathrm{W}$ and $\mathrm{Cu}$ metals, including the cohesive energies, lattice constants, vacancy formation energies, elastic constants and melting points, were calculated using the MD simulation method and the new $\mathrm{W}-\mathrm{Cu}$ potentials to verify the reliability of the $\mathrm{Cu}-\mathrm{Cu}$ and $\mathrm{W}-\mathrm{W}$ potentials. The simulation results and experimental data $[33,34]$ for the cohesive energies, lattice constants, vacancy formation energies, and elastic constants are listed in Table 2. Table 2 shows that the derived $\mathrm{W}-\mathrm{Cu}$ potential works fairly well in reproducing the physical properties of pure $\mathrm{W}$ and $\mathrm{Cu}$.

Table 2. Comparison between the bulk and physical properties of pure $\mathrm{Cu}$ and $\mathrm{W}$ calculated using the present potentials and their reference experimental values.

\begin{tabular}{ccccc}
\hline & \multicolumn{2}{c}{$\mathrm{Cu}$} & \multicolumn{2}{c}{$\mathbf{W}$} \\
\hline & Experimental & Calculated & Experimental & Calculated \\
\hline$a(\AA)$ & 3.615 & 3.615 & 3.16475 & 3.165 \\
$E c(\mathrm{eV})$ & 3.54 & 3.540 & 8.66 & 8.660 \\
$C_{11}(\mathrm{Mbar})$ & 1.7 & 1.700 & 5.326 & 5.326 \\
$C_{12}(\mathrm{Mbar})$ & 1.225 & 1.227 & 2.05 & 2.050 \\
$C_{44}(\mathrm{Mbar})$ & 0.758 & 0.759 & 1.631 & 1.631 \\
$E_{v}(\mathrm{eV})$ & 1.28 & 1.294 & 3.95 & 3.551 \\
\hline
\end{tabular}

Figure 2 shows the densities of $\mathrm{W}$ and $\mathrm{Cu}$ obtained by the TPS method at different temperatures. Thus, the calculated melting points are $1325 \mathrm{~K}$ for $\mathrm{Cu}$ and $3775 \mathrm{~K}$ for $\mathrm{W}$, which are relatively consistent with the experimental values (1358 K and $3695 \mathrm{~K}$, respectively) [35]. The melting point of $\mathrm{W}$ calculated through the W-Cu potential constructed by Gong et al. [19] is approximately $4625 \mathrm{~K}$, which is $930 \mathrm{~K}$ higher than the experimental value.
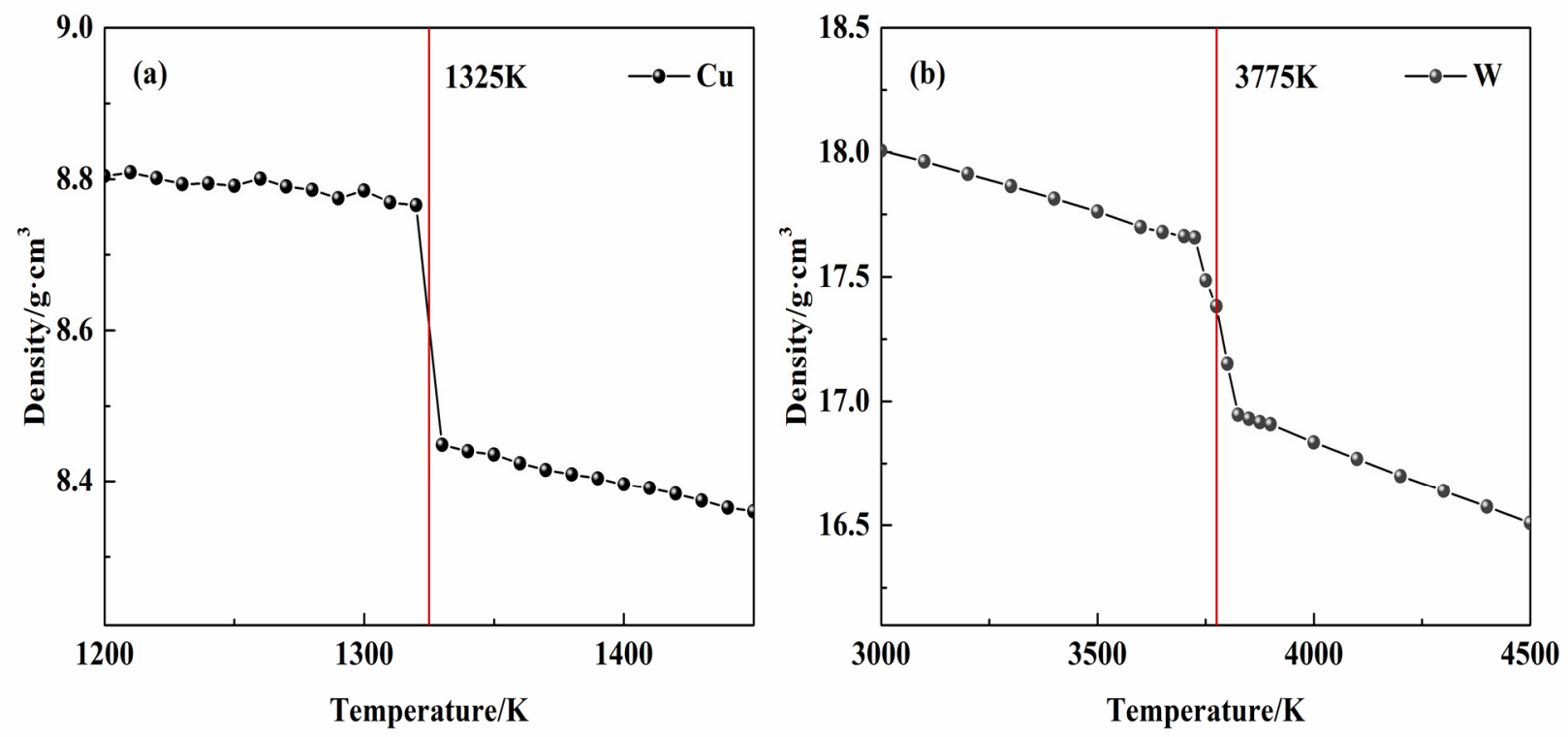

Figure 2. Relationship between (a) $\mathrm{Cu}(\mathbf{b}) \mathrm{W}$ density and temperature.

The cohesive energies and lattice constants of the three nonequilibrium phases, $\mathrm{Cu} 3 \mathrm{~W}$, $\mathrm{CuW}$ and $\mathrm{CuW} 3$, obtained by MD simulations using the new W-Cu potential and ab initio calculations are listed in Table 3. Table 3 shows that the properties calculated from the new $\mathrm{W}-\mathrm{Cu}$ potential are in good agreement with those obtained from ab initio calculations. Evidently, the new W-Cu potential work fairly well in terms of reproducing some physical properties of pure $\mathrm{Cu}$ and $\mathrm{W}$, as well as the nonequilibrium phases in the system. 
Table 3. Lattice constant $a(\AA)$ and cohesive energy $E c(\mathrm{eV})$ of two fictitious solid solutions calculated through the MD method based on the new $\mathrm{W}-\mathrm{Cu}$ potential and ab initio method.

\begin{tabular}{cccccc}
\hline \multirow{2}{*}{ System } & \multirow{2}{*}{ Structure } & \multicolumn{2}{c}{ ab Initio Calculation } & \multicolumn{2}{c}{ Present Study } \\
\cline { 3 - 6 } & & $\boldsymbol{a}(\AA)$ & $\boldsymbol{E c}(\mathbf{e V})$ & $\boldsymbol{a}(\AA)$ & $\boldsymbol{E c}(\mathbf{e V})$ \\
\hline $\mathrm{Cu} 3 \mathrm{~A})$ & $\mathrm{L1}_{2}$ & 3.756 & 4.229 & 3.755 & 4.230 \\
$\mathrm{CuW}$ & $\mathrm{B} 2$ & 3.030 & 5.421 & 3.247 & 5.510 \\
$\mathrm{CuW3}$ & $\mathrm{L} 12$ & 3.910 & 7.041 & 4.132 & 7.213 \\
\hline
\end{tabular}

\subsection{Simulation for Direct Alloying between W and Cu Via the New W-Cu Potential}

As stated above, to understand the atomic-scale structural characteristics of nonequilibrium $\mathrm{W}-\mathrm{Cu}$ alloys, MD simulations were carried out using the $\mathrm{W}-\mathrm{Cu}$ potential. In addition, Zhang et al. [14] proposed that direct alloying between immiscible $\mathrm{W}$ and $\mathrm{Cu}$ near the melting point of $\mathrm{Cu}$ is thermodynamically possible. It is necessary to understand the diffusion mechanism of direct alloying between $\mathrm{W}$ and $\mathrm{Cu}$ at different temperatures close to the melting point of $\mathrm{Cu}$, which is the reason we carried out MD simulations of alloying with the new $\mathrm{W}-\mathrm{Cu}$ potential.

Figure 3 shows the W/Cu interfacial structures obtained through MD simulations of alloying at $1200 \mathrm{~K}$ for different lengths of time. To analyze the distribution of atoms at the interface, the $\mathrm{W}$ block was shifted to the right by $152 \AA$. Figure 3 shows that diffusion occurred between $\mathrm{W}$ and $\mathrm{Cu}$, and the number of atoms involved in diffusion and the diffusion distance increased with time, indicating that direct alloying between $\mathrm{W}$ and $\mathrm{Cu}$ occurred at this temperature. When the simulation time is $0.2 \mathrm{~ns}$, the number of interdiffused atoms is only $0.94 \%$ of the total number of atoms, and the percentage reaches $1.54 \%$ when the simulation time is $2 \mathrm{~ns}$. When the simulation time is $4 \mathrm{~ns}$, the diffusion distance does not increase significantly, indicating that the increase in the diffusion distance tends to stabilize with increasing time. This observation agrees well with the observation by $\mathrm{Chen}$ et al. [32] for a $\mathrm{Cu}-\mathrm{Al}$ system at high temperatures. Meanwhile, Figure 3 shows that the diffusion of the two kinds of atoms is not symmetric. The amount of $\mathrm{Cu}$ atoms diffusing into the $\mathrm{W}$ matrix is greater than that of $\mathrm{W}$ atoms involved in mutual diffusion, and the $\mathrm{W}$ atoms prefer to stay at the interface. This result has also been observed in experiments by Jiang et al. [36] in X-ray diffraction (XRD) tests that were carried out for the $\mathrm{W} / \mathrm{Cu}$ interface constructed through direct alloying. The XRD results show that the $\mathrm{W}$ peaks at the interfaces shift toward larger $2 \theta$ angles, which is the result of the dissolution of $\mathrm{Cu}$ atoms into $\mathrm{W}$. We believe that $\mathrm{Cu}$ diffuses into $\mathrm{W}$ rather than $\mathrm{W}$ into $\mathrm{Cu}$ mainly due to the atomic sizes of $\mathrm{Cu}$ and $\mathrm{W}$. The atomic radius of $\mathrm{W}(\sim 1.40 \AA$ [37]) is larger than that of $\mathrm{Cu}$ $(\sim 1.28 \AA$ [37]). Some studies [32,38] show that atoms with smaller radii more easily diffuse into metals whose atoms have larger radii. Thus, it is not difficult to conclude that $\mathrm{Cu}$ more easily diffuses into $\mathrm{W}$, while $\mathrm{W}$ has relatively difficulty diffusing into $\mathrm{Cu}$ during alloying. The pairwise correlation functions $g(r)$ of the W/Cu interfacial structure at different times are calculated according from the MD simulation results (see Section $C$ of the Supporting Information), which characterize the $\mathrm{W} / \mathrm{Cu}$ alloying structure after alloying.

$\mathrm{MD}$ simulations of the $\mathrm{W}-\mathrm{Cu}$ direct alloying process using the new $\mathrm{W}-\mathrm{Cu}$ potential were carried out in this paper. During the simulations, the alloying temperatures were set at $900 \mathrm{~K}, 1000 \mathrm{~K}, 1100 \mathrm{~K}, 1200 \mathrm{~K}$ and $1300 \mathrm{~K}$, and the alloying time was set at 2 ns. The $\mathrm{W} / \mathrm{Cu}$ interfacial structure and the diffusion curves are shown in Figures 4 and 5, respectively. The regions where the concentration of solute atoms is greater than $5 \%$ are defined as the interface layers [32]. Figure 4 shows that when the alloying temperature is $900 \mathrm{~K}$ (see Figure 4a), the diffusion distance is approximately $4.5 \AA$ (see Figure $5 \mathrm{a}$ ), indicating very little diffusion across the interface. When the alloying temperature is $1000 \mathrm{~K}$ (see Figure $4 \mathrm{~b}$ ), more $\mathrm{Cu}$ atoms begin to diffuse into $\mathrm{W}$, and the structure of $\mathrm{Cu}$ begins to become disordered at the interface. With increasing temperature, the diffusion of $\mathrm{Cu}$ atoms becomes obvious. When the alloying temperature reaches $1200 \mathrm{~K}$ (see Figure $4 \mathrm{~d}$ ), the number of $\mathrm{Cu}$ atoms diffusing into the $\mathrm{W}$ region increases, causing the original ordered 
structure of $W$ to gradually become disordered. At this time, as shown in Figure $5 d$, the thickness of the diffusion layer obtained is approximately $13.5 \AA$. When the temperature reaches $1300 \mathrm{~K}$ (see Figure $4 \mathrm{e}$ ), the diffusion increases significantly, and the diffusion distance reaches $16.5 \AA$ (see Figure 5e).
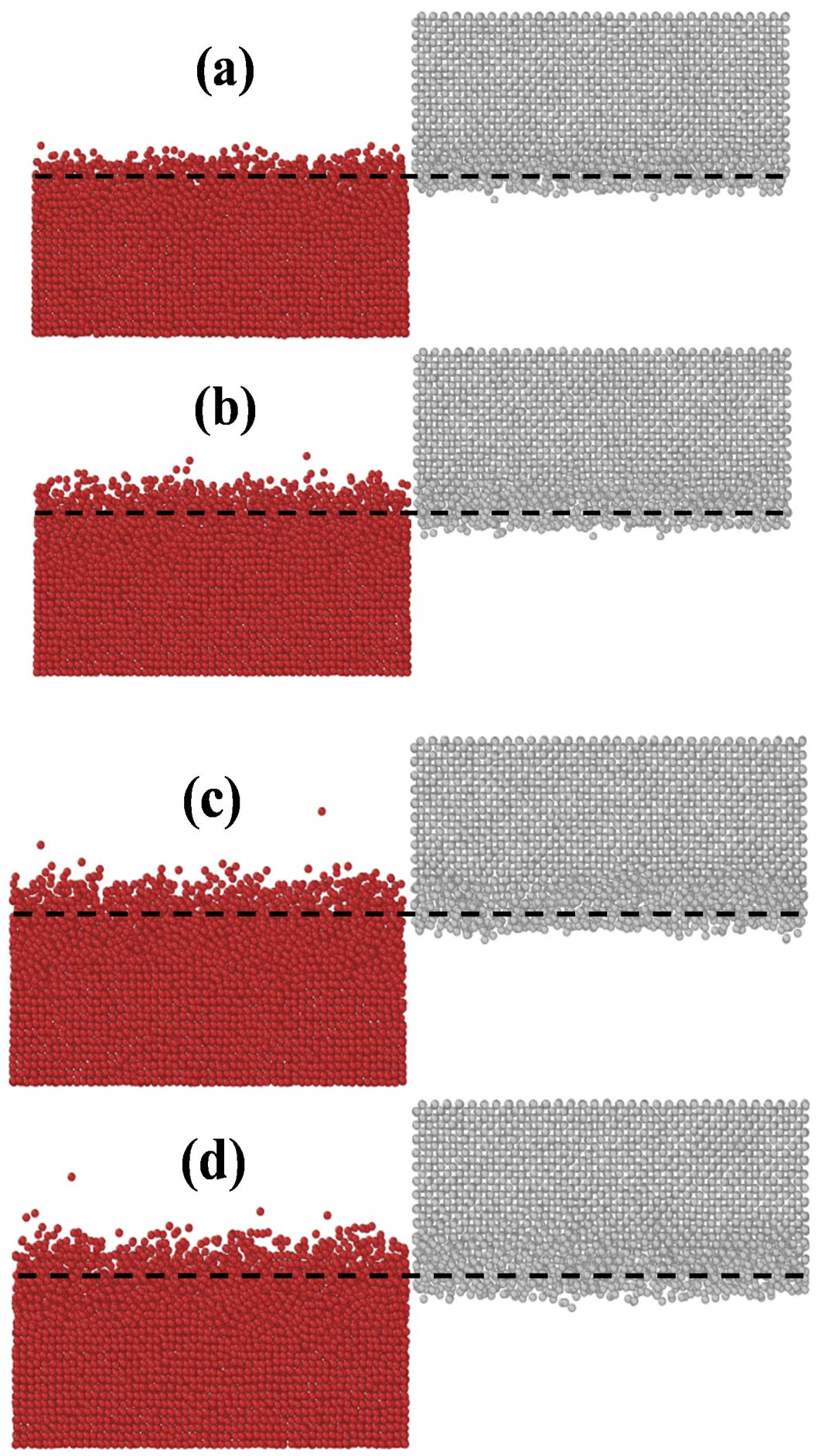

Figure 3. W/ Cu interfacial structures obtained through alloying at a temperature of $1200 \mathrm{~K}$ for different times: (a) $0.2 \mathrm{~ns}$, (b) $1 \mathrm{~ns}$, (c) 2 ns, and (d) 4 ns. The red and gray atoms represent $\mathrm{Cu}$ and $\mathrm{W}$ atoms, respectively. These results are obtained from MD simulations using the new W-Cu potential. 

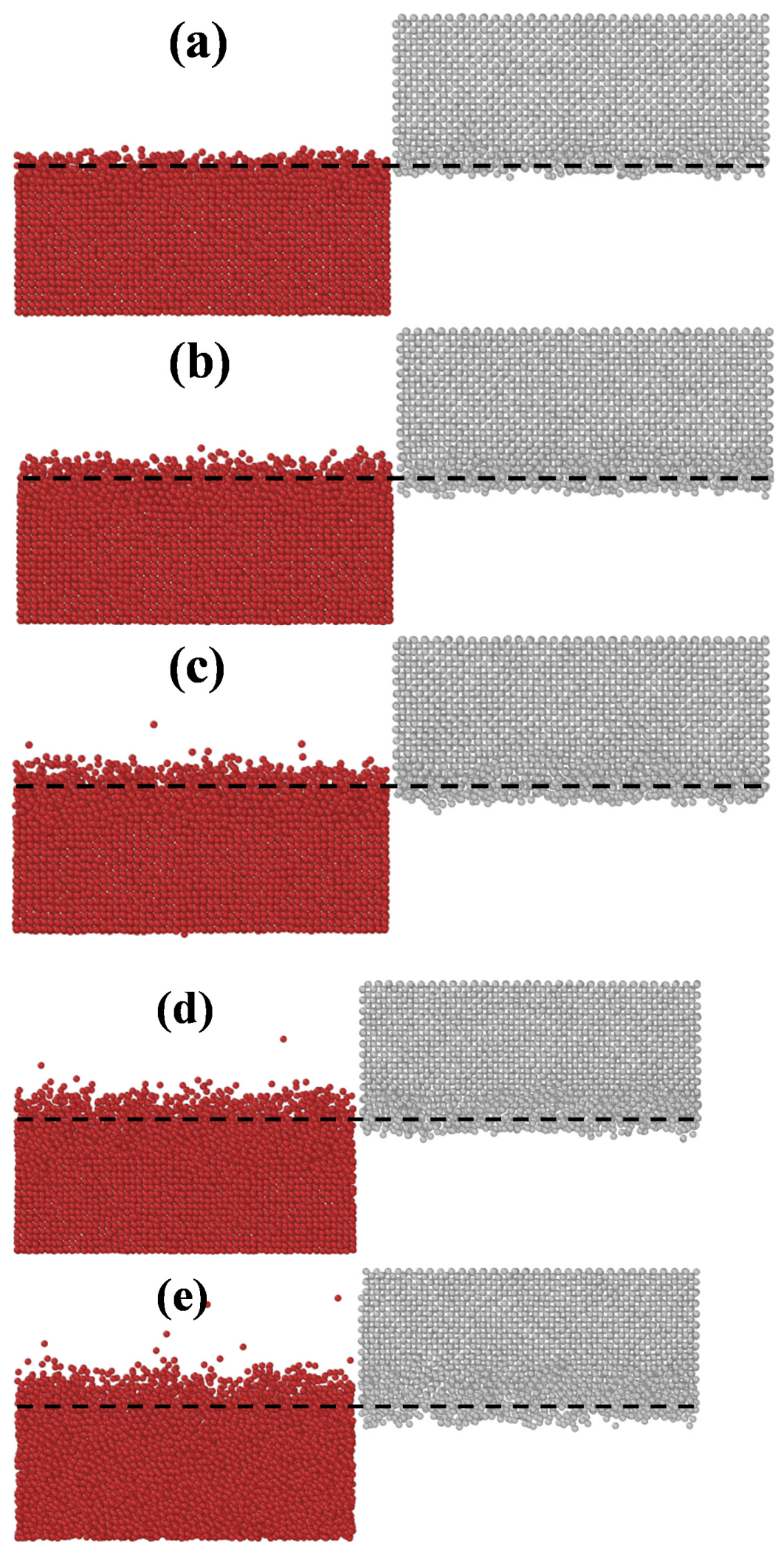

Figure 4. The $\mathrm{W}-\mathrm{Cu}$ interfacial structures after simulation for $2 \mathrm{~ns}$ at different temperatures: (a) $900 \mathrm{~K}$, (b) $1000 \mathrm{~K}$, (c) $1100 \mathrm{~K}$, (d) $1200 \mathrm{~K}$, and (e) $1300 \mathrm{~K}$. The red and gray atoms represent $\mathrm{Cu}$ and $\mathrm{W}$ atoms, respectively. 


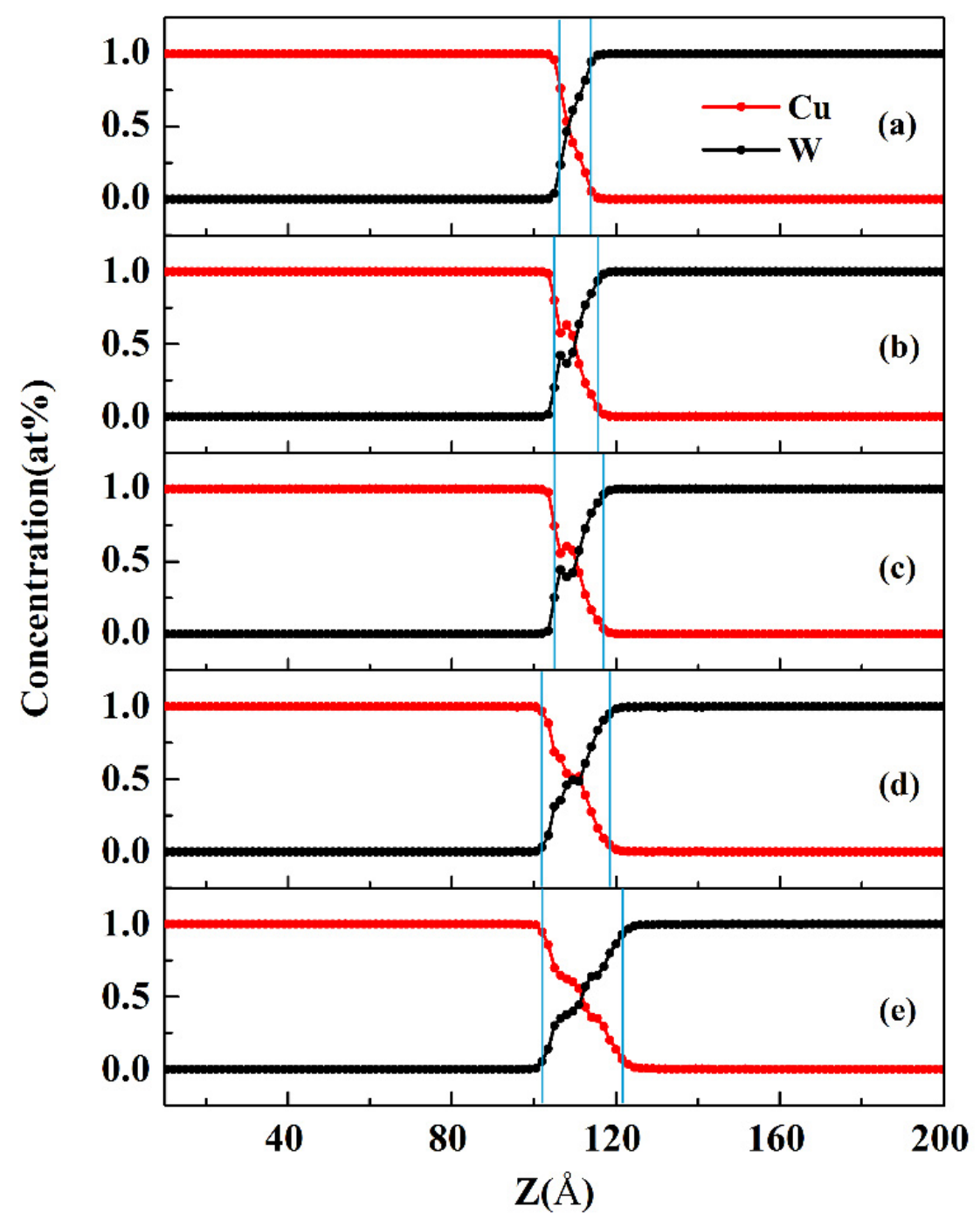

Figure 5. The W-Cu diffusion curves after simulation for $2 \mathrm{~ns}$ at different temperatures: (a) $900 \mathrm{~K}$, (b) $1000 \mathrm{~K}$, (c) $1100 \mathrm{~K}$, (d) $1200 \mathrm{~K}$, and (e) $1300 \mathrm{~K}$.

Obviously, the above simulation results show that the diffusion distance increases rapidly with increasing temperature, and there is a temperature range from $900 \mathrm{~K}$ to less than $\mathrm{T}_{\mathrm{mCu}}$ for alloying between $\mathrm{W}$ and $\mathrm{Cu}$, which is consistent with the experimental results provided by Zhang et al. [14], that the bonding temperatures for $W$ and $\mathrm{Cu}$ should be controlled in an effective temperature range $0.81 \mathrm{~T}_{\mathrm{mCu}}-0.97 \mathrm{~T}_{\mathrm{mCu}}$. This result indicates that the new $\mathrm{W}-\mathrm{Cu}$ potential can reasonably describe the diffusion process in a $\mathrm{W}-\mathrm{Cu}$ system at high temperature. In contrast, when the EAM W-Cu potential presented by Zhou et al. [39] is used to carry out a MD simulation of direct alloying of W and Cu, diffusion is not observed. For another example, when the W-Cu potential constructed by Gong et al. [19] is used to carry out MD simulations of the direct alloying of $\mathrm{W}$ and $\mathrm{Cu}$, diffusion can occur at room temperature, which is unreasonable.

To better understand the mechanism of direct alloying between $\mathrm{W}$ and $\mathrm{Cu}$, some $\mathrm{Cu}$ atoms were labeled using Ovito software. According to the MD simulation results, the particle trajectories of these labeled $\mathrm{Cu}$ atoms were analyzed and are shown in Figure 6. Figure 6 shows that $\mathrm{Cu}$ atoms gradually squeeze into $\mathrm{W}$ with increasing alloying temperature. Meanwhile, the squeezing process leads to structural disorder of $W$, which further promotes the squeezing of $\mathrm{Cu}$ atoms. 


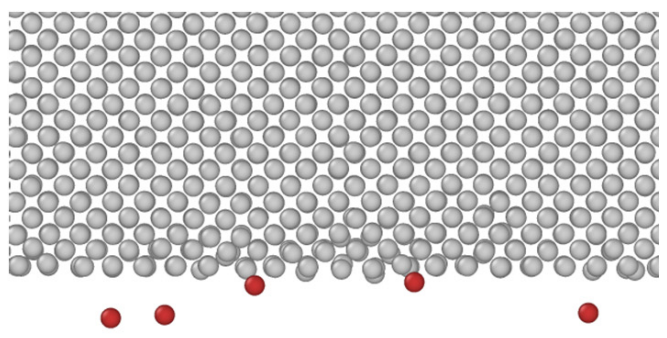

(a)

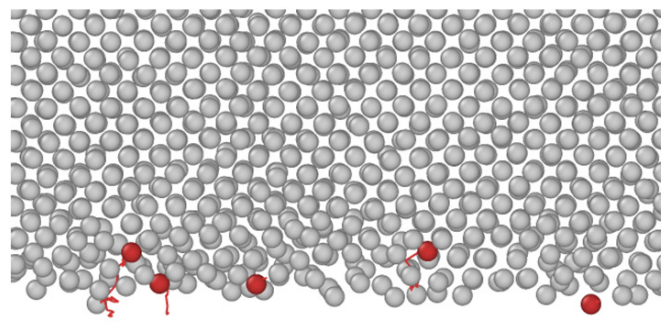

(c)

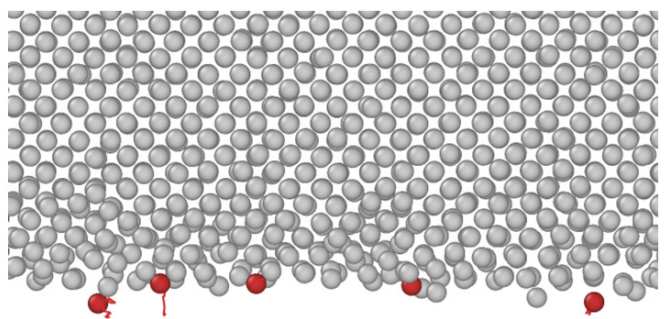

(b)

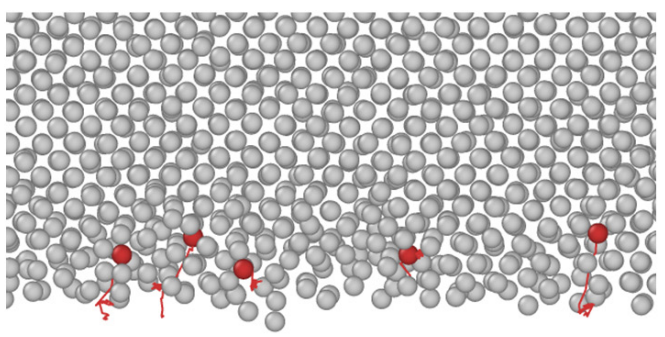

(d)

Figure 6. Particle trajectories of labeled $\mathrm{Cu}$ atoms at different alloying temperatures: (a) $300 \mathrm{~K}$, (b) $900 \mathrm{~K}$, (c) $1100 \mathrm{~K}$, and (d) $1300 \mathrm{~K}$.

The results of the fine-scale density profiles (see Section D of the Supporting Information) also indicate that with increasing alloying temperature, $\mathrm{Cu}$ becomes gradually disordered at and near the interface, while $W$ only becomes disordered at the interface. These analyses support the previous conclusion that during alloying, the structure of $\mathrm{Cu}$ becomes disordered, and the structure of $\mathrm{W}$ becomes relatively relaxed, which weakens the binding strength and motion resistance of $\mathrm{Cu}$ atoms and realizes the diffusion of $\mathrm{Cu}$ atoms into $\mathrm{W}$ metal.

\subsection{Experimental Verification of the New W-Cu Potential}

The results of MD simulation show that there are three main characteristics of $\mathrm{W}-\mathrm{Cu}$ alloying: (1) the temperature range for alloying; (2) mainly $\mathrm{Cu}$ atoms diffuse into W metal during the alloying process; and (3) although the alloying temperature does not reach the melting point of $\mathrm{Cu}$, a disordered amorphous structure develops in the $\mathrm{Cu}$ metal, which makes the $\mathrm{Cu}$ atoms break free from the binding. The first and second points have been verified by previous experimental studies $[12,36]$. To further verify the reliability of the new $\mathrm{W}-\mathrm{Cu}$ potential, it will be necessary to observe the interface after $\mathrm{W}-\mathrm{Cu}$ alloying to confirm the existence of amorphous $\mathrm{Cu}$. Thus, we performed direct alloying experiments of diffusion bonding using $\mathrm{W}$ and $\mathrm{Cu}$ rods, which was the same method used in previous work [12]. In the experiment, the contact surfaces of the $\mathrm{W}$ and $\mathrm{Cu}$ rods were first polished to a mirror finish. Then, high-precision coaxial assembly of the $\mathrm{W}$ and $\mathrm{Cu}$ rods was carried out using a fixture. Finally, the $\mathrm{W}-\mathrm{Cu}$ assembly was annealed in a hydrogen atmosphere at $980^{\circ} \mathrm{C}$ for $180 \mathrm{~min}$ with an external axial pressure of $106 \mathrm{MPa}$. According to our previous studies [14], direct alloying between $\mathrm{W}$ and $\mathrm{Cu}$ can be realized in the range $0.81 \mathrm{~T}_{\mathrm{mCu}} \sim 0.97 \mathrm{~T}_{\mathrm{mCu}}$. Therefore, when annealing was completed, alloying between $\mathrm{W}$ and $\mathrm{Cu}$ was also completed, and there should be a metallurgical bonding interface directly between $\mathrm{W}$ and $\mathrm{Cu}$. Therefore, the characterization of the $\mathrm{W} / \mathrm{Cu}$ interface in the $\mathrm{W} / \mathrm{Cu}$ joint can be used to verify the MD simulation results of direct alloying between $\mathrm{W}$ and $\mathrm{Cu}$ and then verify the new $\mathrm{W}-\mathrm{Cu}$ potential. Characterization of the $\mathrm{W}-\mathrm{Cu}$ interface was carried out with atomic-scale resolution high-angle annular dark-field scanning transmission electron microscopy (HAADF-STEM, JEM-ARM200F). Before interfacial characterization, the W-Cu 
TEM specimens were prepared by cutting the $\mathrm{W} / \mathrm{Cu}$ joint and thinning with the focused ion beam (FIB) technique.

The characterization results are shown in Figure 7, where Figure 7a is a HAADF-STEM image of the W/Cu interface. The insets of Figure $7 \mathrm{a}$ are the corresponding selected areas of electron diffraction (SAED) patterns of the bright and dark areas in Figure 7a. It should be pointed out that the SAED patterns of the bright and dark areas were obtained under different orientations, since there exist deviations in the crystal orientation on both sides of the interface. Inset (A) exhibits a bcc crystal structure along the [001] direction and reveals that the bright area is W. Inset (B) exhibits an fcc crystal structure along the [011] direction and reveals that the dark area is $\mathrm{Cu}$. Figure $7 \mathrm{~b}$ shows the atomic resolution HAADF-STEM images of the region marked with a red rectangle in Figure 7a. The SAED pattern of the region marked with a blue rectangle (Inset (C)) shows that there exists an amorphous region, mainly composed of $\mathrm{Cu}$, at the interface. Because the alloying temperature of $980^{\circ} \mathrm{C}$ does not reach the melting point of $\mathrm{Cu}$, the amorphous region of $\mathrm{Cu}$ should form during alloying rather than melting, which is evidence for the formation of the disordered structure of $\mathrm{Cu}$, as shown by the MD simulation. The third characteristic of W-Cu alloying concluded from the MD simulation results is also confirmed by experimental results, indicating that the new $\mathrm{W}$-Cu potential in this study can accurately model the alloying behavior of immiscible W-Cu systems.
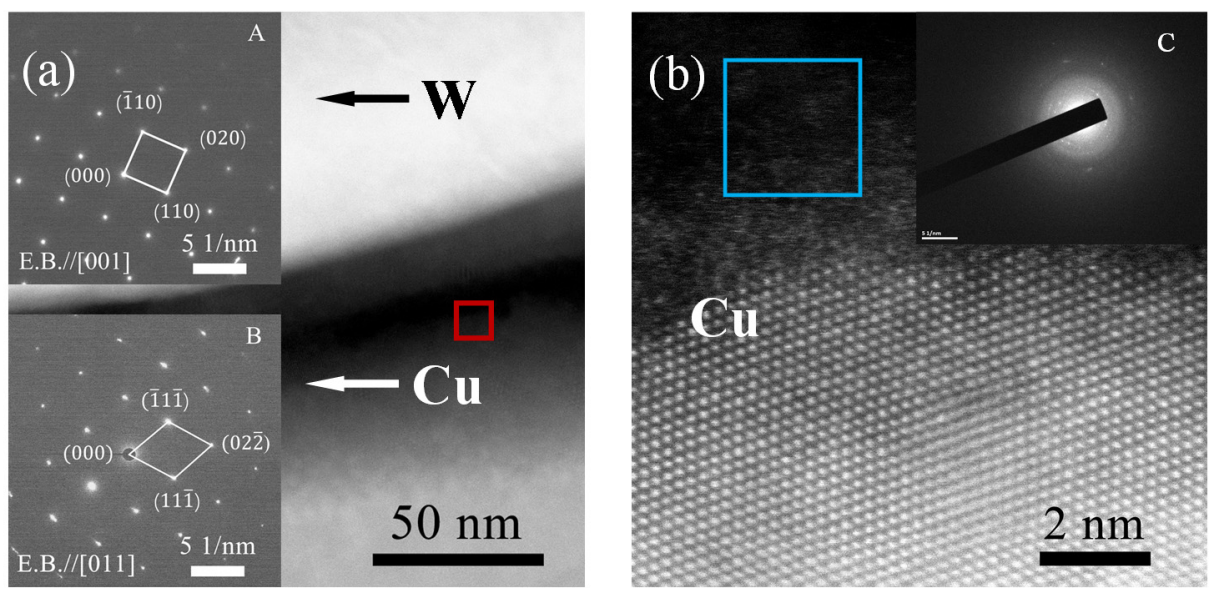

Figure 7. (a) HAADF-STEM image of the $\mathrm{W} / \mathrm{Cu}$ interface through direct alloying at $980{ }^{\circ} \mathrm{C}$; (b) Atomic resolution HAADF-STEM images of the region marked with a red rectangle in (a).

3.4. Fundamental Reason for the Ability of the New Potential to Model the Alloying Behavior of the $\mathrm{W}$-Cu System

We believe that the fundamental reason that the new $\mathrm{W}-\mathrm{Cu}$ potential in this paper can more accurately model the alloying behavior of $\mathrm{W}$ and $\mathrm{Cu}$ at high temperature is that the melting points of the two elements, especially $\mathrm{W}$, have been accurately modeled. The melting point of a pure metal characterizes the mutual attraction between the atoms of the pure metal. The higher the melting point is, the greater the attraction is. Moreover, we think that for a binary metal potential, if the attraction between the pure metal atoms is too large, there are deviations in the attraction between binary metal atoms. These deviations lead to anomalous results when the potential is used to carry out an MD simulation of the alloying of the binary metal system. For example, when the W/Cu EAM potential presented by Gong et al. [19] was used to carry out MD simulations of the melting behavior of $\mathrm{W}$ metal, the simulated melting point of $\mathrm{W}$ was $4625 \mathrm{~K}$, which was much higher than the experimental melting point of $\mathrm{W}$ (3695 [21]). If this W/Cu EAM potential is used to simulate the direct alloying of $\mathrm{W}$ and $\mathrm{Cu}$, diffusion between $\mathrm{W}$ and $\mathrm{Cu}$ can occur at room temperature [19], which is unrealistic. In contrast, the new W-Cu potential in this study can simulate the melting point of $\mathrm{W}$ at $3775 \mathrm{~K}$, which is less than $80 \mathrm{~K}$ from the true melting 
point of $\mathrm{W}$. This enables the new $\mathrm{W}-\mathrm{Cu}$ potential to simulate the $\mathrm{W}-\mathrm{Cu}$ alloying behavior, which agrees closely with our previous experimental results.

\section{Conclusions}

To study the diffusion mechanism for direct alloying between $\mathrm{W}$ and $\mathrm{Cu}$ in a temperature range close to the melting point of $\mathrm{Cu}$ and facilitate the preparation of $\mathrm{W}-\mathrm{Cu}$ composite materials, a suitable $\mathrm{W}-\mathrm{Cu}$ potential is constructed in this paper. This $\mathrm{W}-\mathrm{Cu}$ potential takes the form of an F-S potential that combines the original F-S potential form for the $\mathrm{W}-\mathrm{W}$ potential with the extended F-S potential form for the $\mathrm{Cu}-\mathrm{Cu}$ potential and the $\mathrm{W}-\mathrm{Cu}$ component. The construction process shows that to successfully develop an interatomic potential for an immiscible system, whether the new interatomic potential can accurately simulate the melting point of a high-melting-point constituent element in the system is a very important standard.

Validation by theoretical calculations and experiments shows that the new W-Cu potential is reliable and the method of developing the $\mathrm{W}-\mathrm{Cu}$ potential is reasonable. First, the new $\mathrm{W}-\mathrm{Cu}$ potential can be used to accurately simulate physical properties, such as the cohesive energies, lattice constants, vacancy formation energies, elastic constants and melting points, of pure $\mathrm{W}$ and $\mathrm{Cu}$ through the molecular dynamics method (MD). The calculated melting points of $1325 \mathrm{~K}$ for $\mathrm{Cu}$ and $3775 \mathrm{~K}$ for W, are relatively consistent with the actual melting points of $\mathrm{Cu}(1358 \mathrm{~K})$ and $\mathrm{W}(3695 \mathrm{~K})$, respectively. Second, the new $\mathrm{W}-\mathrm{Cu}$ potential can be successfully used to simulate direct alloying of $\mathrm{W}$ and $\mathrm{Cu}$ through $\mathrm{MD}$. The simulation results show that the $\mathrm{Cu}$ atoms mainly diffuse into the $\mathrm{W}$ metal rather than the $\mathrm{W}$ atoms diffusing into the $\mathrm{Cu}$ metal during alloying, and a disordered structure develops in the $\mathrm{Cu}$ metal and makes the $\mathrm{Cu}$ atoms break free from binding of the metal, promoting diffusion. These simulation results are in good agreement with experimental results.

Supplementary Materials: The following are available online at https: / www.mdpi.com/article / 10.3390/ma14205988/s1, Figure S1: The structures of the fictitious W-Cu solid solutions, Figure S2: Calculated total energy versus average atomic volume for the B2 and L12 structures, Figure S3: Pair correlation functions for (a) initial structure and (b) W-Cu interfacial structure obtained through alloying at $1200 \mathrm{~K}$ for 2 ns, Figure S4: Fine-scale density profiles $(\rho(Z))$ for $\mathrm{W}$ and Cu near and at the $\mathrm{W}-\mathrm{Cu}$ interface constructed through direct alloying at different temperatures, Table S1: Parameters obtained for the W-W potential parts of the W-Cu potential, Table S2: Lattice constant a ( $\mathrm{A})$ and cohesive energy Ec $(\mathrm{eV})$ of two fictitious solid solutions calculated through the ab initio method.

Author Contributions: Conceptualization, T.Z. and Y.H.; methodology, T.Z. and Y.H.; software, T.Z. and F.L.; validation, T.Z. and F.L.; formal analysis, T.Z. and F.L.; investigation, T.Z.; resources, Y.H.; data curation, Y.H.; writing-original draft preparation, T.Z.; writing-review and editing, F.L. and Y.H.; visualization, T.Z.; supervision, Y.H.; project administration, Y.H.; funding acquisition, Y.H. All authors have read and agreed to the published version of the manuscript.

Funding: This research was funded by the National Key Research and Development Program of China (Grant Nos. 2018YFB0703904 and 2017YFE0302600), and the National Natural Science Foundation of China (Grant No. 51471114).

Institutional Review Board Statement: Not applicable.

Informed Consent Statement: Not applicable.

Data Availability Statement: The raw/processed data required to reproduce these findings can be found in this paper.

Acknowledgments: The authors are grateful to Jinfeng Zhang for her help in TEM sample preparation.

Conflicts of Interest: The authors declare no conflict of interest. 


\section{References}

1. Ryu, S.S.; Kim, Y.D.; Moon, I.H. Dilatometric analysis on the sintering behavior of nanocrystalline W-Cu prepared by mechanical alloying. J. Alloys Compd. 2002, 335, 233-240. [CrossRef]

2. Chen, P.A.; Shen, Q.; Luo, G.Q.; Wang, C.B.; Li, M.J.; Zhang, L.M.; Li, X.C.; Zhu, B.Q. Effect of interface modification by Cu-coated $\mathrm{W}$ powders on the microstructure evolution and properties improvement for $\mathrm{Cu}-\mathrm{W}$ composites. Surf. Coat. Technol. 2016, 288, 8-14. [CrossRef]

3. Chen, W.G.; Dong, L.L.; Zhang, H.; Song, J.L.; Deng, N.; Wang, J.J. Microstructure characterization of W-Cu alloy sheets produced by high temperature and high pressure deformation technique. Mater. Lett. 2017, 205, 198-201. [CrossRef]

4. Boer, F.R.d.; Mattens, W.C.M.; Boom, R.; Miedema, A.R.; Niessen, A.K. Cohesion in Metals. Transition Metal Alloys; North-Holland: Amsterdam, The Netherlands, 1988; 774p.

5. Liang, C.P.; Wu, C.Y.; Fan, J.L.; Gong, H.R. Structural, thermodynamic, and mechanical properties of WCu solid solutions. J. Phys. Chem. Solids 2017, 110, 401-408. [CrossRef]

6. Vullers, F.T.N.; Spolenak, R. From solid solutions to fully phase separated interpenetrating networks in sputter deposited "immiscible" W-Cu thin films. Acta Mater. 2015, 99, 213-227. [CrossRef]

7. Tabrizi, N.S.; Xu, Q.; van der Pers, N.M.; Schmidt-Ott, A. Generation of mixed metallic nanoparticles from immiscible metals by spark discharge. J. Nanopart. Res. 2010, 12, 247-259. [CrossRef]

8. Ai, Y.P.; Xie, S.K.; Zeng, Y.Y.; Yi, R.X.; Wang, J.T. Research on Cu-W homogeneous film structure prepared by ion beam sputtering. J. Alloys Compd. 2010, 496, 385-387. [CrossRef]

9. Nastasi, M.; Saris, F.W.; Hung, L.S.; Mayer, J.W. Stability of amorphous Cu/Ta and Cu/W alloys. J. Appl. Phys. 1985, 58, 3052-3058. [CrossRef]

10. Zhang, D.L. Processing of advanced materials using high-energy mechanical milling. Prog. Mater. Sci. 2004, 49, 537-560. [CrossRef]

11. Zhang, R.F.; Li, Z.C.; Liu, B.X. Metastable phase formed in immiscible Cu-W multilayers by ion mixing. Jpn. J. Appl. Phys. Part 1 2003, 42, 7009-7012. [CrossRef]

12. Zhang, J.; Huang, Y.; Liu, Y.; Wang, Z. Direct diffusion bonding of immiscible tungsten and copper at temperature close to Copper's melting point. Mater. Des. 2018, 137. [CrossRef]

13. Huang, Y.; Du, J.; Wang, Z. Progress in research on the alloying of binary immiscible metals. Acta Metall. Sin. 2020, 56, 801-820.

14. Zhang, J.; Huang, Y.; Wang, Z.; Liu, Y. Thermodynamic mechanism for direct alloying of immiscible tungsten and copper at a critical temperature range. J. Alloys Compd. 2018, 774, 939-947. [CrossRef]

15. Lv, X.J.; Guan, C.H.; Han, Z.X.; Zhang, H.B.; Liu, Q.S. The wetting characteristics of copper droplets on tungsten surfaces on atomic scale: A molecular dynamics simulation. Comput. Mater. Sci. 2020, 174, 109487. [CrossRef]

16. Wei, W.; Chen, L.; Gong, H.R.; Fan, J.L. Strain-stress relationship and dislocation evolution of W-Cu bilayers from a constructed n-body W-Cu potential. J. Phys. Condens. Matter. 2019, 31, 305002. [CrossRef]

17. Xiu, L.; Wu, J.F. Atomic Diffusion Behavior in W/Cu Diffusion Bonding Process. J. Fusion Energy 2015, 34, 769-773. [CrossRef]

18. Zhang, R.F.; Kong, L.T.; Gong, H.R.; Liu, B.X. Comparative study of metastable phase formation in the immiscible Cu-W system byab initiocalculation andn-body potential. J. Phys. Condens. Matter. 2004, 16, 5251-5258. [CrossRef]

19. Gong, H.R.; Kong, L.T.; Lai, W.S.; Liu, B.X. Glass-forming ability determined by ann-body potential in a highly immiscible Cu-W system through molecular dynamics simulations. Phys. Rev. B 2003, 68, 144201. [CrossRef]

20. Kong, L.T.; Li, X.Y.; Lai, W.S.; Liu, J.B.; Liu, B.X. Interfacial reaction of W/Cu examined by an n-body potential through molecular dynamics simulations. Jpn. J. Appl. Phys. Part 1 2002, 41, 4503-4508. [CrossRef]

21. Lide, D.R. CRC Handbook of Chemistry and Physics, 81st ed.; CRC Press: Boca Raton, FL, USA, 2000.

22. Finnis, M.W.; Sinclair, J.E. A simple empirical N-body potential for transition metals. Philos. Mag. A 1984, 50, 45-55. [CrossRef]

23. Ackland, G.J.; Finnis, M.W.; Vitek, V. Validity of the second moment tight-binding model. J. Phys. F Met. Phys. 1988, 18, L153-L157. [CrossRef]

24. Ackland, G.J.; Tichy, G.; Vitek, V.; Finnis, M.W. Simple N-body potentials for the noble metals and nickel. Philos. Mag. A 1987, 56, 735-756. [CrossRef]

25. Tai, K.P.; Dai, X.D.; Shen, Y.X.; Liu, B.X. Formation and Structural Anomaly of the Metastable Phases in an Immiscible Ag-Mo System Studied by Ion Beam Mixing and Molecular Dynamics Simulation. J. Phys. Chem. B 2005, 110, 595-606. [CrossRef]

26. Dai, X.D.; Li, J.H.; Guo, H.B.; Liu, B.X. Structural stability and characteristics of the metastable Ag-W phases studied by ab initio and molecular dynamics calculations. J. Appl. Phys. 2007, 101, 063512. [CrossRef]

27. Bryk, T.; Demchuk, T.; Jakse, N.; Wax, J.F. A Search for Two Types of Transverse Excitations in Liquid Polyvalent Metals at Ambient Pressure: An Ab Initio Molecular Dynamics Study of Collective Excitations in Liquid Al, Tl, and Ni. Front. Phys. 2018, 6, 6. [CrossRef]

28. Kresse, G.; Furthmüller, J. Efficient iterative schemes for ab initio total-energy calculations using a plane-wave basis set. Phys. Rev. B 1996, 54, 11169-11186. [CrossRef] [PubMed]

29. Arima, T.; Idemitsu, K.; Inagaki, Y.; Tsujita, Y.; Kinoshita, M.; Yakub, E. Evaluation of melting point of $\mathrm{UO}_{2}$ by molecular dynamics simulation. J. Nucl. Mater. 2009, 389, 149-154. [CrossRef]

30. Plimpton, S. Fast Parallel Algorithms for Short-Range Molecular-Dynamics. J. Comput. Phys. 1995, 117, 1-19. [CrossRef] 
31. Luo, M.Z.; Liang, L.; Lang, L.; Xiao, S.F.; Hu, W.Y.; Deng, H.Q. Molecular dynamics simulations of the characteristics of Mo/Ti interfaces. Comput. Mater. Sci. 2018, 141, 293-301. [CrossRef]

32. Chen, S.D.; Ke, F.J.; Zhou, M.; Bai, Y.L. Atomistic investigation of the effects of temperature and surface roughness on diffusion bonding between $\mathrm{Cu}$ and Al. Acta Mater. 2007, 55, 3169-3175. [CrossRef]

33. Gale, W.F.; Totemeier, T.C. Smithells Metals Reference Book; Elsevier: Amsterdam, The Netherlands, 2003.

34. Simmons, G. Single Crystal Elastic Constants and Calculated Aggregate Progress. J. Grad. Res. Cent. 1965, $34,273$.

35. Dai, X.D.; Kong, Y.; Li, J.H.; Liu, B.X. Extended Finnis-Sinclair potential for bcc and fcc metals and alloys. J. Phys. Condens. Matter. 2006, 18, 4527-4542. [CrossRef]

36. Jiang, D.F.; Long, J.Y.; Cai, M.Y.; Lin, Y.; Fan, P.X.; Zhang, H.J.; Zhong, M.L. Femtosecond laser fabricated micro/nano interface structures toward enhanced bonding strength and heat transfer capability of W/Cu joining. Mater. Des. 2017, 114, 185-193. [CrossRef]

37. Benenson, W.; Harris, J.W.; Stocker, H. Handbook of Physics; Springer: New York, NY, USA, 2002.

38. Richmond, O.; Morrison, H.; Devenpeck, M. Sphere indentation with application to the Brinell hardness test. Int. J. Mech. Sci. 1974, 16, 75-82. [CrossRef]

39. Zhou, X.W.; Johnson, R.A.; Wadley, H.N.G. Misfit-energy-increasing dislocations in vapor-deposited CoFe/NiFe multilayers. Phys. Rev. B 2004, 69, 144113. [CrossRef] 